\title{
Dynamic Measurement and Evaluation of Hotel Customer Satisfaction Through Sentiment Analysis on Online Reviews
}

\author{
Gang Zhou, Chongqing University, Chongqing, China \& Chongqing Normal University, Chongqing, China \\ Chenglin Liao, Chongqing University, Chongqing, China
}

\begin{abstract}
In the hotel industry, the measurement and evaluation of customer satisfaction is the principal tool for marketers to assess the health of their relationships with customers. Online review (OR) is an important vehicle of the measured and evaluated results. In recent years, both academia and the industry have attached great importance to the measurement and evaluation of customer satisfaction based on online reviews. However, there are several problems with the satisfaction measurement and evaluation of hotel customers: the diverse dimensions of indices, the static method of measurement, and the contradiction between conclusions. Thus, it is urgent to standardize the theories, methods, and techniques for measurement and evaluation. The purpose of this study is to propose a dynamic measurement and evaluation framework for hotel customer satisfaction through sentiment analysis on online reviews. The proposed framework consists of five steps: (1) The corpus of online reviews is obtained, laying a data basis for subsequent research. (2) From the perspective of managers, the useful texts are recognized through review preprocessing, word segmentation, extraction of highfrequency words, topic extraction, phrase processing, and selection of subjective phrases. (3) Based on the recognized useful texts, a three-layer index system is created for hotel customer satisfaction according to relevant professional theories. (4) The center term-based short sentence sentimental orientation (CTSSSO) algorithm is developed to compute emotional intensity, calculate index weight based on word frequency statistics, and then dynamically measure the customer satisfaction. (5) The dynamic important performance competitor analysis (DIPCA) is adopted for dynamic evaluation of customer satisfaction. The feasibility of the framework and its specific methods were demonstrated through a case study on the online reviews of two five-star hotels on Ctrip.com and comparison against the conclusions in relevant literature and manual tags.
\end{abstract}

\section{KEYWORDS}

CTSSSO Algorithm, Customer Satisfaction, DIPCA, Dynamic Measurement and Evaluation, Framework, Hotel, Method, Online Reviews, Sentiment Analysis

\section{INTRODUCTION}

In recent years, China has seen a boom of hotel demand and a double-digit growth of the number of hotels. Overall, customers are quite satisfied with hotel services. However, some indices of customer

DOI: $10.4018 /$ JOEUC.20211101.oa8

This article published as an Open Access article distributed under the terms of the Creative Commons Attribution License (http://creativecommons.org/licenses/by/4.0/) which permits unrestricted use, distribution, and production in any medium, provided the author of the original work and original publication source are properly credited. 
satisfaction remain at a low level all year round (Jointwisdom, 2020). What is worse, there is a declining trend in the recognition of hotels in more than half cities and provinces across the country (China Hospitality Association, 2019). This raises three important questions: Are the current index systems for customer satisfaction scientific and reasonable? Are the evaluation processes and methods scientific? Are the evaluation results objective enough to reflect the reality? These questions became even more important after the outbreak of the COVID-19. Scientific methods and techniques should be adopted to understand the subjective needs of customers, improve service quality, and fully manage customer satisfaction.

Satisfaction is the key to the competitive advantage of a hotel. Amid fierce market competition, the hotel should make customer satisfaction its top priority. Customer satisfaction measurement and evaluation is the principal tool by which marketers assess the health of their relationships with their customers (Rossomme, 2003). The aim of measuring and evaluating customer satisfaction is to assess the quality of existing management practices and suggest directions for improvement (Gilbert \& Horsnell, 1998). Traditionally, customer satisfaction is measured and evaluated through quantitative statistics and structural equation modeling (SEM), based on the data collected from questionnaire survey, interview, and case study. This traditional strategy consumes lots of time and manpower, and yet outputs information of poor quality (Decker \& Trusov, 2010; Groves, 2006). Under this strategy, the measurement and evaluation are basically static, focusing on one or several time points or periods. To make matters worse, the relevant evaluation researches emphasize the indices of customer satisfaction over those of customers before and after the purchase, and lack comparative analysis on customer satisfaction of competing enterprises.

Online reviews are the real feelings expressed by hotel customers after consuming and experiencing products and services. They are often considered as spontaneous and insightful feedbacks from customers. These free or low-cost feedbacks can be obtained anytime, anywhere (Guo et al., 2017). Moreover, online reviews have good dynamic features due to their time tags. Based on online reviews of hotel customers, it is possible to set up a complete index system involving pre-purchase indices (e.g., expectation), in-purchase indices (e.g., satisfaction and service quality), and post-purchase indices (e.g., complaint), revealing the spatial and temporal dynamics of customer satisfaction.

Through the above analysis, this paper proposes a dynamic measurement and evaluation framework and its specific methods for hotel customer satisfaction through sentiment analysis on online reviews. The dynamic measurement and evaluation were realized based on a self-designed scientific index system for customer satisfaction. The feasibility of our framework was proved through case study.

\section{RELATED WORKS}

\subsection{Hotel Customer Satisfaction}

There is not yet a well-accepted definition of customer satisfaction. Based on the expectancy disconfirmation model (EDM), Oliver (1986) considered customer satisfaction as an overall emotional response of customers after comparing the perception and expectation of product/service quality. The degree of customer satisfaction is usually measured with an index called customer satisfaction degree (CSD). The growth of hotel customer satisfaction helps to improve the customer loyalty (Ismail, 2019; Kandampully \& Suhartanto, 2000), overall reputation (Kim \& Kim, 2017), and profitability (Assaf et al., 2015) of the hotel. Facing intensified competitions, hotels are increasingly aware of the importance of customer satisfaction.

To measure and evaluate customer satisfaction, one must anticipate which dimensions or attributes of the product or service customers use in their overall quality assessment (Pizam et al., 2016), and construct an index system for customer satisfaction. Service quality dimension makes a significant contribution to the prediction of customer satisfaction (Amin et al., 2013). The gap that may exist between the customers' expected and perceived service is not only a measure of the quality of the 
service, but is also a determinant of customer satisfaction/dissatisfaction (Pizam \& Ellis, 1999). Therefore, the dimensions of service quality, as an antecedent of customer satisfaction, can often be directly used as the dimensions in the measurement and evaluation of customer satisfaction (Zhang \& Li, 2009; Pizam et al., 2016; Shafiq et al., 2019). The attributes of customer satisfaction have always been the topics of its measurement and evaluation (Li et al., 2013; Xu \& Li, 2016; Rahimi \& Kozak, 2017; Davras \& Caber, 2019; Nunkoo et al., 2020).

Apart from the dimensions of the antecedent and its own attributes, the outcome variables of customer satisfaction have also been incorporated by some scholars into the measurement and evaluation index system. The most common outcome variables include customer loyalty and customer complaint. The American Customer Satisfaction Index (ACSI) and its improved models have been the mainstream tools for measuring and evaluating customer satisfaction (Kim et al., 2013; Deng et al., 2013) (Table 1). The ACSI was extended by Fornell et al. (1996) from Swedish Customer Satisfaction Barometer (SCSB). The ACSI involves six structural variables, including a target variable (customer satisfaction), three antecedent variables (customer expectation, perceived quality, and perceived value), and two outcome variables (customer loyalty and customer complaint). Kim et al. (2013) test the validity of the ACSI model specifically for the hotel industry, the theoretical underpinnings and conceptual foundation of the model can be used as a basis for customer satisfaction research. Judging by the dimensions of satisfaction indices, the existing online data-based methods for measurement and evaluation of customer satisfaction (Li et al., 2013; Xu \& Li, 2016; Pacheco, 2017) only consider the antecedent and the own attributes, without involving outcome variables (Table 1).

The customer satisfaction system is a whole. The antecedent and outcomes must be considered, in addition to its own attributes, in order to effectively measure and evaluate customer satisfaction. Based on the six structural variables of the ACSI, this paper distinguishes between the various indices before setting up an index system for hotel customer satisfaction.

The attribute measurement must focus on the important attributes related to customer needs. Thus, it is necessary to measure the importance of each attribute of the customer (Pizam et al., 2016). There are usually two methods of importance measurement: stated-importance and derived-importance approaches. Chu (2002) held that the stated-importance approach is better at measuring customer satisfaction than the derive-importance approach. Once the index dimensions and importance are determined, it is possible to construct an measurement and evaluation index system of customer satisfaction.

The popular ways to measure and evaluate customer satisfaction include importance-performance analysis (IPA) (Martilla \& James, 1977), service quality (SERVQUAL) scale/service performance (SERVPERF) scale (PZB, 1985,1988; Cronin \& Taylor, 1992,1994), customer satisfaction index model (Fornell et al., 1996; Kristensen et al., 1999), expectation-performance model, analytic hierarchy process (AHP) (Gupta \& Srivastava, 2011), Kano model (Kano et al., 1984), principal component analysis (PCA) (Ferrari \& Manzi, 2010), fuzzy comprehensive evaluation (FCE) (Wei et al., 2015), and grey relational analysis (GRA) (Yao, 2012). As the name implies, the measurement and evaluation customer satisfaction consist of two processes: measurement and evaluation.

Measurement is the basis of evaluation. Among the above models, AHP, PCA, FCE, SERVQUAL/ SERVPERF model, and customer satisfaction index model focus more on measurement; IPA, expectation-performance model, Kano model, and GRA focus more on evaluation. The previous studies on hotel customer satisfaction have not differentiated between measurement and evaluation. The scholars either emphasize on measurement or evaluation, failing to fully utilize the features and merits of different models. Moreover, the evaluation results of some scholars are not necessarily accurate, due to the lack of scientific basis for measurement. Aklimawati \& Hartatri (2019), and Pizam et al. (2016) mainly tackled the measurement of hotel customer satisfaction, while Cai et al. (2021), Tsai et al. (2020), and Albayrak \& Caber (2015) paid more attentions to the evaluation of hotel customer satisfaction. Only Babi-Hodovi et al. (2019) and Beheshtinia \& Azad (2019) well integrated measurement and evaluation methods for hotel customer satisfaction. In this paper, hotel 
Table 1. The measurement and evaluation dimensions of hotel customer satisfaction in recent studies

\begin{tabular}{|c|c|c|}
\hline Authors & Dimensions of customer satisfaction & Methodology \\
\hline Zhang \& Li (2009) & $\begin{array}{l}\text { The staff's behavior, Comfort, Individuation, The hotel's } \\
\text { development }\end{array}$ & $\begin{array}{l}\text { Questionnaire, Factor } \\
\text { analysis }\end{array}$ \\
\hline Li et al. (2013) & $\begin{array}{l}\text { Logistics, Facilities, Reception services, Food and beverage } \\
\text { management, Cleanliness and maintenance, Value for } \\
\text { money }\end{array}$ & $\begin{array}{l}\text { Online customer reviews, } \\
\text { Text mining and content } \\
\text { analysis }\end{array}$ \\
\hline Deng et al. (2013) & $\begin{array}{l}\text { Consumption emotions, Service quality, Perceived value, } \\
\text { Overall customer satisfaction index, Customer loyalty }\end{array}$ & $\begin{array}{l}\text { Questionnaire, H-CSI } \\
\text { model, Partial least square }\end{array}$ \\
\hline Kim et al. (2013) & $\begin{array}{l}\text { Perceived quality, Customer expectations, Perceived value, } \\
\text { Satisfaction, Customer Complaints, Customer loyalty }\end{array}$ & $\begin{array}{l}\text { ACSI hotel data from ACSI } \\
\text { national data, Structural } \\
\text { equation modeling }\end{array}$ \\
\hline Xu \& Li (2016) & $\begin{array}{l}\text { Location and accessibility, Staff performance, Room } \\
\text { quality, Value, Food, Environment }\end{array}$ & $\begin{array}{l}\text { Online customer reviews, } \\
\text { Latent semantic analysis }\end{array}$ \\
\hline Pizam et al. (2016) & $\begin{array}{l}\text { The material product in a narrow sense, The behavior and } \\
\text { attitude of the employees, The environment }\end{array}$ & Literature review \\
\hline Pacheco (2017) & $\begin{array}{l}\text { Room, Comfort, Service, Cleanliness, Value, Location, } \\
\text { Facilities }\end{array}$ & $\begin{array}{l}\text { Online customer reviews, } \\
\text { OLS regression analysis }\end{array}$ \\
\hline Rahimi \& Kozak (2017) & $\begin{array}{l}\text { Room decoration, Hotel cleanliness, Bed comfort, Value } \\
\text { for money }\end{array}$ & $\begin{array}{l}\text { Interview, Descriptive } \\
\text { analysis, Word cloud }\end{array}$ \\
\hline Shafiq et al. (2019) & Tangible, Reliability, Responsiveness, Assurance, Empathy & $\begin{array}{l}\text { Questionnaire, Multiple } \\
\text { linear regression }\end{array}$ \\
\hline Davras \& Caber (2019) & $\begin{array}{l}\text { Entertainment services, Restaurant services, Cleaning of } \\
\text { general areas, Service staff, Foreign language knowledge of } \\
\text { staff, Extra services, Front office services, Housekeeping } \\
\text { services }\end{array}$ & $\begin{array}{l}\text { Questionnaire, Multi- } \\
\text { variable regression }\end{array}$ \\
\hline Nunkoo et al. (2020) & $\begin{array}{l}\text { Accommodation infrastructure, Room quality, Front } \\
\text { desk, Food and beverage, Sociability, Safety and security, } \\
\text { Attitude and behavior of employees, Employee expertise, } \\
\text { Customer interaction, Waiting time }\end{array}$ & $\begin{array}{l}\text { Questionnaire, PLS-SEM } \\
\text { Partial least square - } \\
\text { Structural equation } \\
\text { modeling }\end{array}$ \\
\hline
\end{tabular}

customer satisfaction is measured by SERVQUAL/SERVPERF scale and customer satisfaction index model, and evaluated by the IPA, aiming to achieve good effects of measurement and evaluation.

The SERVQUAL scale is a new service quality evaluation system for the service industry. The scale was proposed by Parasuraman, Zeithaml and Berry $(1985 ; 1988)$ according to the theory of total quality management (TQM). The core of the SERVQUAL scale is the gap model of service quality. The service quality depends on the degree of difference between expected and perceived service levels. Cronin \& Taylor $(1992 ; 1994)$ held that it is unscientific to simultaneously measure expected and perceived performances, and proposed the SERVPERF scale that measures service quality solely based on service performance. Ho et al. (2013) integrated SERVQUAL to help identify the core attributes of service quality that effectively improve hotel customer satisfaction. Babi-Hodovi et al. (2019) developed conceptualizations of the SERVPERF scale, and determined which of them is outstanding in predicting hotel customer satisfaction. Service quality is the most important antecedent variable of customer satisfaction. It is scientific to measure and evaluate hotel customer satisfaction with the models/scales for the measuring and evaluating service quality.

Proposed by Martilla \& James (1977), the IPA believes that the customer satisfaction with a product/service comes from the importance of the key attributes of the product/service in the eyes of customers and the performance of these key attributes. Albayrak \& Caber (2015) added the competitor factor to the traditional IPA, and modified the approach into importance-performance competitor 
analysis (IPCA). Considering the time dimension, Bi et al. (2019) created the dynamic IPA (DIPA) to measure the dynamic changes and change trend of important attributes of service quality. Bi et al. (2019) further extended the DIPA into the dynamic important performance competitor analysis (DIPCA), which reveals the performance changes of the target enterprise (focal enterprise) and its competitor in different periods.

Currently, hotel customer satisfaction is usually measured and evaluated based on the data collected from questionnaire surveys and interviews (Table 1). There are multiple defects with this approach: the data acquisition is time-consuming and costly; the quality of the questionnaire is restricted by the respondents and contents; the collected data only reflect the situation in one or several time points. The questionnaire-based studies on satisfaction belong to static research, such as the survey, measurement, and analysis of hotel customer satisfaction by Rahimi \& Kozak (2017), Eygu \& Gulluce (2017), and Al \& Wahidul (2020). Compared with the data collected by questionnaire surveys, online reviews have many advantages: the contents are dynamically updated in real time, the reviews reflect the real feelings of customers, the data can accurately and objectively reflect the gap between customer expectation and actual perception, and the reviews can be acquired at a low cost.

Static satisfaction is more in line with specific transaction satisfaction, while dynamic satisfaction fits better with cumulative satisfaction. Customer satisfaction is not static, but changes with the elapse of time, the progress of technology, and the improvement of the environment. It is essentially a concept of cumulative satisfaction. The dynamics of measurement and evaluation for customer satisfaction come from the dynamics of demand. The customer satisfaction has been systematically measured and evaluated in relevant industries, namely, aviation (Lucini et al., 2020) and manufacturing (Jiang et al., 2017; Chan et al., 2020). Nevertheless, the existing studies mostly analyze hotel customer satisfaction statically, focusing on one or several time points. This problem could be solved by using the time tags of online reviews. But only a few scholars have resorted to them. For example, Zhang et al. (2020) provided a multi-stage multi-attribute decision-making method that applies to the dynamic measurement and evaluation of hotel customer satisfaction.

Based on online reviews, this paper considers antecedent, own attributes, and outcome variables in the construction of index system for customer satisfaction, and measures and evaluates hotel customer satisfaction from different time dimensions (week, month, season, and year), revealing its dynamic trend and evolution mechanism.

\subsection{Topic Extraction}

The topic is the key information expressed in the corpus files of online reviews. Topic extraction refers to mining the key information from the text through textual analysis. It is an important means to overcome the high-dimensional sparsity of space vectors and to improve the retrieval quality. The topic extraction methods are generally based on statistical features, semantic rules, or topic models.

The most common statistical feature-based methods are word frequency statistics, word frequency co-occurrence matrix, synonym forest (Tongyici Cilin), word2vec, term frequency-inverse document frequency (TF-IDF) algorithm. Specifically, the word frequency statistics counts the frequency of word appearances in a preprocessed file, weights the words in the file according to the frequency, and selects words with relatively high weight as topics. For example, Hu \& Liu (2004) designed a framework for feature extraction, which takes high-frequency nouns and phrases as candidate topic features. Although capable of extracting high-frequency words, the word frequency statistics can neither extract low-frequency words nor classify high-frequency words. To complete topic extraction, this method must be assisted by other methods and professional theories. This paper adopts the term frequency approach, which has been proved effective in sentiment classification (Archak et al., 2011; Hu et al., 2014).

Word similarity has been widely applied in topic extraction. In most cases, word similarity is calculated based on semantic dictionaries, e.g., Tongyici Cilin (extended) (HIT-SCIR, 2012) (HITCIR: The Research Center for Social Computing and Information Retrieval, Harbin Institute of 
Technology) and HowNet Knowledge Database (Dong \& Dong, 2013). That is, the similarity between two words is calculated based on the arrangement and semantic features of synonym forest, making word search and replacement more comprehensive and accurate. Li et al. (2018) preprocessed texts by replacing words with Tongyici Cilin. Sun et al. (2019) relied on HowNet to compute the semantic similarity of aspect words.

In 2013, Mikolov et al. (2013) launched word2vec, an opensource tool for calculating word vectors. Based on a given corpus, word2vec can express words in vector form quickly and effectively, using an optimized training model, and extract the eigenvector of each word in the light of the context; the similarity in the vector space reflects the semantic similarity of the text. Zhang et al. (2015) used word2vec to cluster the similar features, and demonstrated that this approach can effectively capture the semantic features in selected domain and Chinese language. Demir et al. (2020) employed word2vec to represent 11 hotel attributes with words of similar meanings.

From the perspectives of syntax and semantics, the semantic rule-based methods set up rules according to human habits of thinking and ways of linguistic expressions, construct the structure of word network, and then obtain the topic of the target file. Kang \& Zhou (2017) proposed rule-based extraction (RubE)-unsupervised rule-based methods to extract both subjective and objective features from online customer reviews. Through experiments, Wang et al. (2017) learned that rule-based topic extraction is inferior to machine learning algorithms. Some scholars have explored semantic-rule based methods in hotel industry. For instance, Freitas \& Viera (2013) identified features in hotel review data with ontology method. In general, it is difficult to define rules for complex online texts. The difficulty is even greater if the texts are in Chinese, which features complex structure and diverse expressions.

The topic model-based methods mainly acquire the hidden topics in the text through modelling. The most classic topic model is the latent Dirichlet allocation (LDA) model developed by Blei et al. (2003). Guo et al. (2017), Akhtar et al. (2017), and Priyantina \& Sarno (2019) adopted the LDA to identify the key dimensions of customer service for hotel visitors. Nevertheless, the LDA model performs poorly in extracting topics from short texts like online reviews, because data sparsity and ambiguity arise from the lack of context. Neither could the improved versions of the LDA, namely, the biterm topic model (BTM) (Yan et al., 2013), achieve a desirable performance, for they still regard a text as a bag of words (BOW).

Considering the features of review texts, this paper builds an index system for hotel customer satisfaction mainly by extracting the topics from online reviews based on statistical features, supplemented by semantic rules and topic models.

\subsection{Sentiment Analysis}

Sentiment analysis is a technique to extract, analyze, process, summarize, and deduce the subjective contents generated by Internet users. This technique combines the merits of multiple disciplines, ranging from natural language processing, machine learning, text mining, information extraction and retrieval, to probability statistics. Through sentiment analysis, the text contents of the reviews on a product/service are automatically analyzed to disclose customer attitudes and opinions of the product/ service, qualitatively judge their sentimental orientations (e.g., commendation/derogation, like/dislike, and support/opposition) of the text, and evaluate the intensity of the sentimental orientations (Pang \& Lee, 2008). Based on the granularity of the object, sentiment analysis falls into four levels of granularity: document-level, sentence-level, phrase-level, and feature-level (Fu et al., 2017). Neither document-level nor sentence-level granularity reflects the exact likes or dislikes (Liu, 2010). Besides, it is extremely challenging to study the opinion text on the feature-level (Freitas \& Vieira, 2013). The classification of emotions and sentiments into coarse-grained classes does not always reflect the exact state of mood or opinion of a user. Hence, the research attention has shifted towards fine-grained analysis on the continuous scale (Akhtar et al., 2018). Currently, emotional intensity or sentimental orientation has attracted a growing attention from the academia. The calculation of emotional intensity 
Figure 1. Framework of dynamic measurement and evaluation for hotel customer satisfaction based on sentimental analysis of online reviews

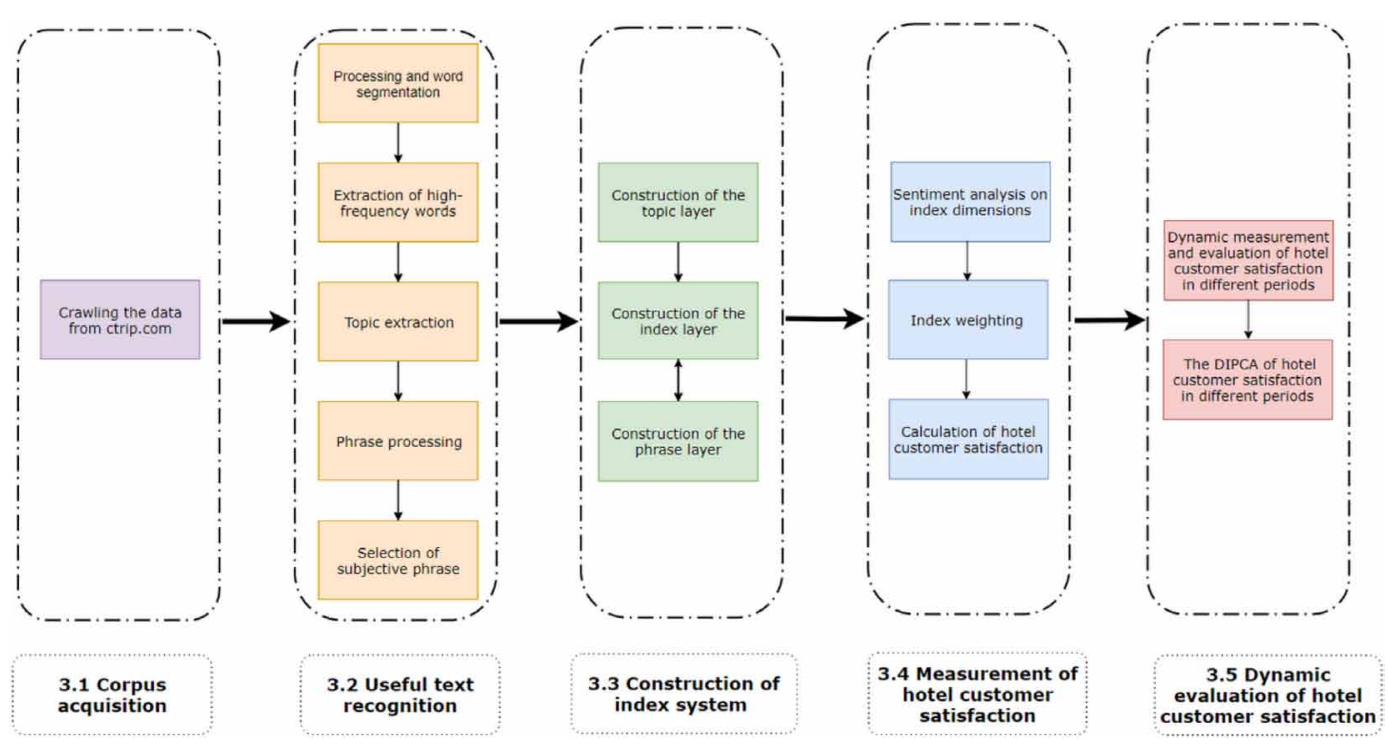

or sentimental orientation is usually realized by constructing an emotional intensity dictionary (Yu et al., 2017; Elsaid et al., 2018; Chen et al., 2019).

At present, there are not many sentiment analyses on hotel customer satisfaction. The existing sentiment analyses mainly concentrate on the whole sentences of reviews (Duan et al., 2013) and the short sentences of reviews (Khotimah \& Sarno, 2019). Besides, these analyses stop at emotion classification, failing to address the intensity/orientation of emotion (Luo et al., 2020; Chang et al., 2020; Freitas \&Vieira, 2013). Among the few scholars engaging in emotional intensity or sentimental orientation, Pekar \& Ou (2008) and Tao et al. (2019) measured the emotional intensity of guests for each feature by the average emotional values.

In addition, there is little report that dynamically tracks and analyzes the emotional intensity through different periods. Therefore, this paper focuses on analyzing the polarity and intensity of emotions in phrases and attributes in online reviews, in order to reveal the dynamic changes of emotions related to customer satisfaction as a whole and in each dimension.

\section{RESEARCH DESIGN}

This paper presents a framework for dynamic measurement and evaluation of hotel customer satisfaction based on sentimental analysis of online reviews. As shown in Figure 1, there are five steps in the framework: (1) corpus acquisition; (2) useful text recognition; (3) construction of index system; (4) dynamic measurement of hotel customer satisfaction; (5) dynamic evaluation of hotel customer satisfaction.

\subsection{Corpus Acquisition}

Ctrip.com (https://www.ctrip.com/), a leading hotel booking service provider in China, holds a hotel reservation network of more than 600,000 member hotels in and outside China. It boasts more hotel reviews, better review quality, and greater influence than other Chinese online travel agencies (OTAs). Hence, this paper crawls the data from ctrip.com, including such fields as hotel name, reviewer information, review content, rating, check-in time, and review usefulness. 


\subsection{Useful Text Recognition}

Helpfulness is meaningful for hoteliers to improve their service quality and for readers to make decisions (Fang et al., 2016). Qi et al. (2016) suggested that usefulness of online reviews can be judged from the perspective of customers and the perspective of product designers. The latter perspective is adopted here, and extended into the perspective of business manager.

\subsubsection{Preprocessing and Word Segmentation}

Step 1. The invalid reviews are removed, and traditional Chinese is converted into simplified Chinese. The invalid reviews refer to the reviews that are entirely symbols, numbers, emojis, or in foreign language, and those containing fewer than 4 Chinese characters.

Step 2 . The user dictionary is customized by adding vocabularies related to hotel industry, OTA platform, emotions, and research cases.

Step 3. The reviews are segmented into words, and the part-of-speech (POS) of each word is tagged with the Language Technology Platform (LTP) (Che et al., 2010).

Step 4. The stop words are filtered out from the reviews against the stop word list issued by the HIT.

Step 5. The word frequencies are counted. If corrections are necessary, a new cycle should be initiated from Step 2 to Step 5.

Step 6 . The high-frequency words are identified, and the synonyms are merged, before outputting high-frequency words.

\subsubsection{Extraction of High-Frequency Words}

High-frequency words refer to words that appear frequently in the set and are frequently used. These words usually contain important information. In this paper, the number of high-frequency words is determined by Donohue's (1973) calculation method of the boundary value $n$ between high- and low-frequency words:

$$
n=\frac{-1+\sqrt{1+8 I_{1}}}{2}
$$

where, $I_{1}$ is the number of words with the frequency of 1 .

\subsubsection{Topic Extraction}

Considering the strengths and weaknesses of the three kinds of topic extraction methods, this paper mainly extracts the topics from the short texts of online reviews based on statistical features, supplemented by semantic rules and topic models. The main steps of topic extraction are as follows:

Step 1. A total of $n_{1}$ high-frequency words is obtained by formula (1).

Step 2. The word $2 \mathrm{vec}$ model is adopted to predict the context of the high-frequency words, and express the words as vectors, producing the training file. Then, the cosine angle between each pair of vectors is calculated, which represents the similarity between the corresponding words. The words bearing greater-than- $80 \%$ similarity with high-frequency words are analyzed, and taken as the candidates for the expansion of high-frequency word set. Next, the synonyms of the candidates are merged, followed by another cycle of preprocessing, word segmentation, and high-frequency word extraction. In this way, $\mathrm{n}_{2}$ new high-frequency words are obtained. 
Step 3. The similarity between words is calculated by the hybrid method of HIT-CIR Tongyici Cilin and HowNet (Yaleimeng, 2019), and the synonyms are replaced based on professional knowledge, producing $\mathrm{n}_{3}$ new high-frequency words.

Step 4. The NetDraw visualizations software is adopted to analyze the word frequency co-occurrence of $n_{3}$ high-frequency words, and the high-frequency word set is further expanded based on the co-occurrence matrix, resulting in $\mathrm{n}_{4}$ new high-frequency words. Then, the topics of $\mathrm{k}_{1}$ categories are determined through visual clustering of high-frequency words.

Step 5. Despite its poor effect on short texts like online reviews, the LDA is performed to cluster the topics, because the analysis results provide a good reference for topic classification. The number of reference topics is defined as the intersection between the number of topics before the inflecting point of the decline segment of the perplexity curve and the number of topics at the points of the peak consistency. Then, the topics of $\mathrm{k}_{2}$ categories are selected based on the visualization model, serving as the reference for the number of topics.

Step 6. Drawing on the relevant index systems for customer satisfaction, the high-frequency words are added, reduced, and merged based on the ACSI and other theories on customer behavior and customer relationship management. In this way, a total of $n_{5}$ topic keywords (high-frequency words) are obtained, forming the topics of $\mathrm{k}_{3}$ categories.

\subsubsection{Phrase Processing}

The review texts corresponding to the topic keywords were searched for. Then, the truncated corpus was processed and matched with dictionary based on punctuation marks, creating the review corpus of each topic keyword. For simplicity and readability, the smallest phrase was taken as the unit of corpus processing. The review texts were split into phrases by commas, semicolons, full stops, question marks and exclamation marks in Chinese and English. Considering the special nature of hotel text corpus, Chinese and English spacings, tildes, and ellipses were also adopted as the criteria for phrase truncation.

\subsubsection{Selection of Subjective Phrases}

Subjective phrases describe the author's thoughts or opinions on things, persons, or events, which are inevitably emotional. As fact-based description of events, and objects, objective phrases do not have any personal preference or prejudice. The classification between subjective and objective texts is the primary task in sentiment analysis.

This paper employs the Naive Bayes classifier to determine subjective and objective phrases based on the probability of emotional polarity: the phrases whose probability of emotional polarity falls in 0.4-0.6 are objective, and those whose probability of emotional polarity falls outside that interval are subjective. Only subjective phrases were subject to sentiment analysis.

\subsection{Construction of Index System}

Based on the results of topic extraction, phrase processing, and selection of subjective phrases, a three-layer index system was created for hotel customer satisfaction under the guidance of professional theories: the first layer (the topic layer) contains the topics of $\mathrm{k}_{3}$ categories, the second layer (the index layer) contains $\mathrm{n}_{5}$ topic keywords, and the third layer (the phrase layer) contains the review phrases corresponding to the topic keywords, which are the basic unit of the measurement and evaluation of hotel customer satisfaction.

\subsection{Dynamic Measurement of Hotel Customer Satisfaction}

\subsubsection{Sentiment Analysis on Index Dimensions}

The hotel customer satisfaction was measured by the emotional intensity of online review corpus. In natural language processing, the emotional intensity is usually measured by sentiment dictionary 


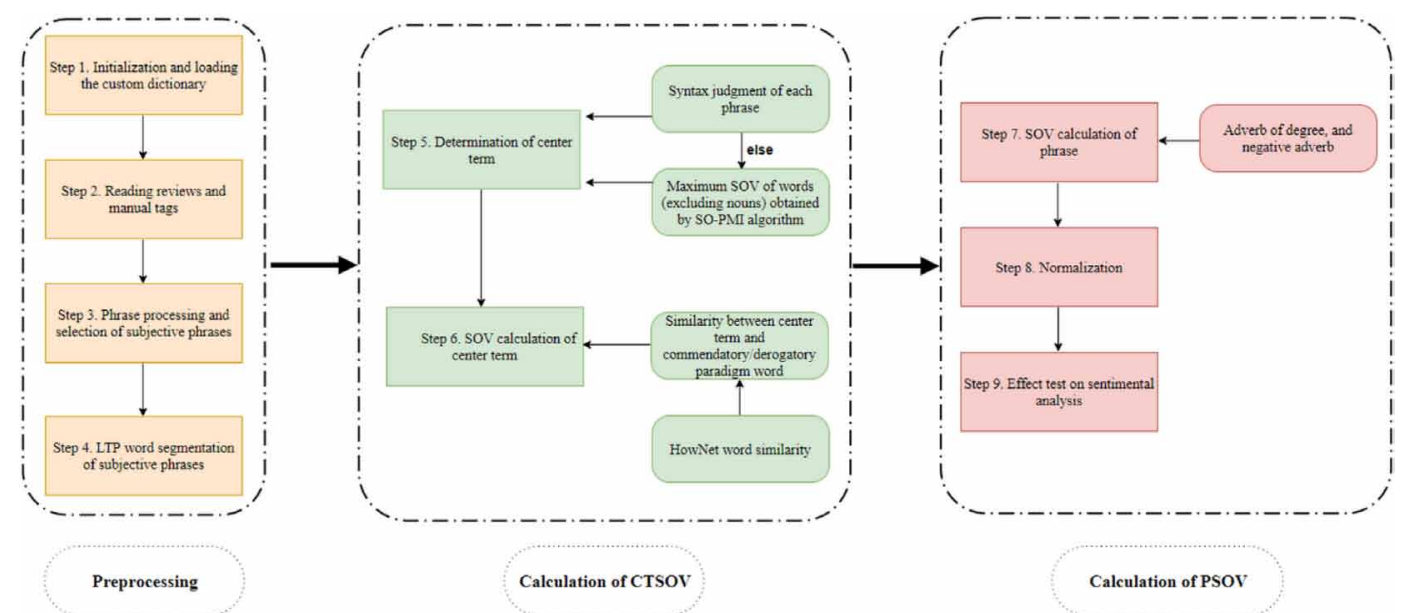

plus syntactic structure. Hence, the center emotional terms (hereinafter referred to as the center terms) were determined by the authoritative Chinese sentiment dictionary of HowNet (Dong \& Dong, 2013; (Dong \& Dong, 2003), with the aid of common syntactic structures. Besides, the sentimental orientation values (SOVs) of center terms were calculated by the semantic orientation-pointwise mutual information (SO-PMI) algorithm. Hence, a novel algorithm was developed: the center termbased short sentence sentimental orientation (CTSSSO) algorithm. The main ideas of the proposed algorithm are as follows (Figure 2):

Step 1 . The algorithm is initialized by loading the custom dictionary, adverbs of degree, and negative adverbs.

Step 2. The data on reviews and manual tags are read.

Step 3. Based on the results of 3.2 Useful Text Recognition, the objective phrases are deleted, leaving only the subjective ones.

Step 4. The remaining subjective phrases are subject to LTP segmentation, and the stop words are deleted.

Step 5. Analysis shows that most phrases have only one topic, and only one center term. Thus, our algorithm only considers the presence of a single center term. According to the internal grammatical structure of the phrases, there are several common syntaxes: verb/adjective + "de (verb modifier)" + verb/adjective, adverb of degree + adjective/adverb, and adjective/adverb + adverb of degree. The verbs, adjectives, and adverbs are selected as center terms.

Step 6. The SOVs of the above center terms are calculated by the SO-PMI algorithm. If no center term is obtained in a phrase through the above POS judgement, all the words other than nouns in that phrase will be traversed, and the SOV of each word will be calculated by the SO-PMI algorithm. Then, the word with the highest SOV will be taken as the center term. In other words, the topic with the highest SOV will be selected as the judgement basis for a phrase containing multiple topics.

The SOV of each center term is calculated in the following steps:

First, the similarity between two words is calculated by the word similarity formula of HowNet (Liu \& Li, 2002): 
$\operatorname{Sim}\left(w, w_{2}\right)=\max _{\mathrm{i}=1 . . \mathrm{n}, \mathrm{j}=1 . . \mathrm{m}} \operatorname{Sim}\left(\mathrm{s}_{1 i}, \mathrm{~s}_{2 j}\right)$

where, $w_{1}$ and $w_{2}$ are two Chinese characters; $\mathrm{S}_{1 i}$ and $\mathrm{S}_{2 j}$ are the meanings (concepts) of $w_{1}$ and $w_{2}$, respectively.

Then, k pairs of commendatory and derogatory paradigm words are selected by the SO-PMI algorithm. The SOV of a center term (CTSOV) equals the similarity of the term with the commendatory paradigm word subtracted by the similarity of the term with the corresponding derogatory paradigm word (Wen et al., 2012):

$$
\operatorname{CTSOV}(w)=\left(\sum_{i=1}^{k} \operatorname{Sim}(k e y-p i, w)-\sum_{j=1}^{k} \operatorname{Sim}(k e y-n j, w)\right) / k
$$

where, $k$ is the number of paradigm word pairs; $k e y-p i$ is a set of commendatory paradigm words with tags like "expected" or "recommended" extracted from HowNet knowledge; key - ni is a set of derogatory paradigm words with tags like "not expected" or "not recommended" extracted from HowNet knowledge; $\operatorname{Sim}(k e y-p i, w)$ is the distance of a word to a commendatory paradigm word; $\operatorname{Sim}(k e y-n j, w)$ is the distance of a word to a derogatory paradigm word.

Step 7. After the CTSOV of each center term is obtained, the adverb of degree and negative adverb before and after that center term are found. Then, the value of adverb of degree are multiplied with the CTSOV to obtain the phrase SOV (PSOV):

$$
\operatorname{PSOV}\left(w_{i}\right)=\prod_{1}^{i} \text { Value }_{a d v} * \operatorname{CTSOV}\left(w_{i}\right)
$$

where, Value $_{a d v}$ is the value of adverb of degree and negative adverb; $i$ is the number of adverbs. By our method, a total of 117 adverbs of degree are selected, whose values fall between 0.8 and 1.5; a total of 32 negative adverbs are selected, whose values range from -1 to -0.6 .

Step 8. The PSOVs are normalized and outputted as a file.

Step 9. The effect of sentimental analysis is tested.

To verify the scientific nature of the above sentimental analysis, the tested emotional intensities are compared with manually tagged values. The absolute error between them is defined as the allowable error range. By this definition, the comparison between the two becomes a binary classification test. Specifically, the representative large corpus is chosen from the samples, and the emotional intensities of the corpus are tagged manually in the interval of $[0,1]$. Meanwhile, the emotional intensities of the corpus are tested, and the obtained scores are normalized to the interval of $[0,1]$. Then, the classification accuracy is calculated within the allowable error range, and used to judge the test effect of our algorithm. 


\subsubsection{Index Weighting}

The importance of an index in the evaluation system of hotel customer satisfaction is reflected by its weight. The weight is generally calculated through Boolean weighting, frequency weighting, and TF-IDF weighting. Considering the good effect of word frequency statistics in sentiment classification (Archak et al., 2011; Hu et al., 2014), frequency weighting was adopted in the weight analysis.

The weight of each index was calculated according to term frequency (TF). The higher the frequency of the word of an index, the greater the TF of the word, and the larger the weight of the index:

$$
T F\left(w_{i}\right)=\frac{T_{i}}{\sum T_{i}}(i=1,2,3 \ldots I)
$$

where, $T F\left(w_{i}\right)$ is the weight of index $w_{i} ; \mathrm{T}_{i}$ is the number of appearances of index $T$ in review set; $\sum T_{i}$ is the size of the review set.

\subsubsection{Calculation of Hotel Customer Satisfaction}

Based on a self-designed index system, hotel customer satisfaction was calculated by the weighted average method:

$$
\operatorname{HCSD}(w)=\sum\left[T F\left(w_{i}\right) \operatorname{PSOV}\left(w_{i}\right)\right]
$$

where, $\operatorname{HCSD}(w)$ is the hotel customer satisfaction degree with index $w ; T F\left(w_{i}\right)$ is the weight of the $w_{i}$-th index; PSOV $\left(w_{i}\right)$ is the SOV of the $w_{i}$-th index.

Through the above sentiment analysis and index weighting, it is possible to calculate the comprehensive customer satisfaction of each period, as well as the customer satisfaction of each class of topics and the overall customer satisfaction of all classes of topics. The measurement of customer satisfaction in different periods is highly dynamic.

\subsection{Dynamic Evaluation of Hotel Customer Satisfaction}

\subsubsection{Dynamic Measurement of Hotel Customer Satisfaction in Different Periods}

The corpus of hotel customer satisfaction was divided into $i$ periods according to the check-in time. The corpus in each period was measured and evaluated by the above method, producing the overall satisfaction $H_{i}$ in each period. Meanwhile, each index was divided into $i$ periods according to the check-in time. The sub-index $K$ in each period was also measured and evaluated by the above method, producing the single-index satisfaction $H-K_{i}$ in each period. Then, the $H_{i}$ values and $H-K_{i}$ values were deployed in a coordinate system with time as the $\mathrm{x}$-axis and hotel customer satisfaction as the $y$-axis. On this basis, the hotel customer satisfaction in each period can be evaluated dynamically.

\subsubsection{The DIPCA of Hotel Customer Satisfaction in Different Periods}

There is a premise for applying the DIPCA: the contrastive hotels must belong to the same type with the same positioning, and the product/service elements must have the same weight. Following the DIPCA, the performance difference (PD) between focal hotel and competitor in hotel customer satisfaction was taken as the x-axis, and the gap score of (GAP) between normalized perceived performance ( $\overline{\text { Performance }}$ ) and normalized customer expectation ( $\overline{\text { Importance }}$ ) of the focal 


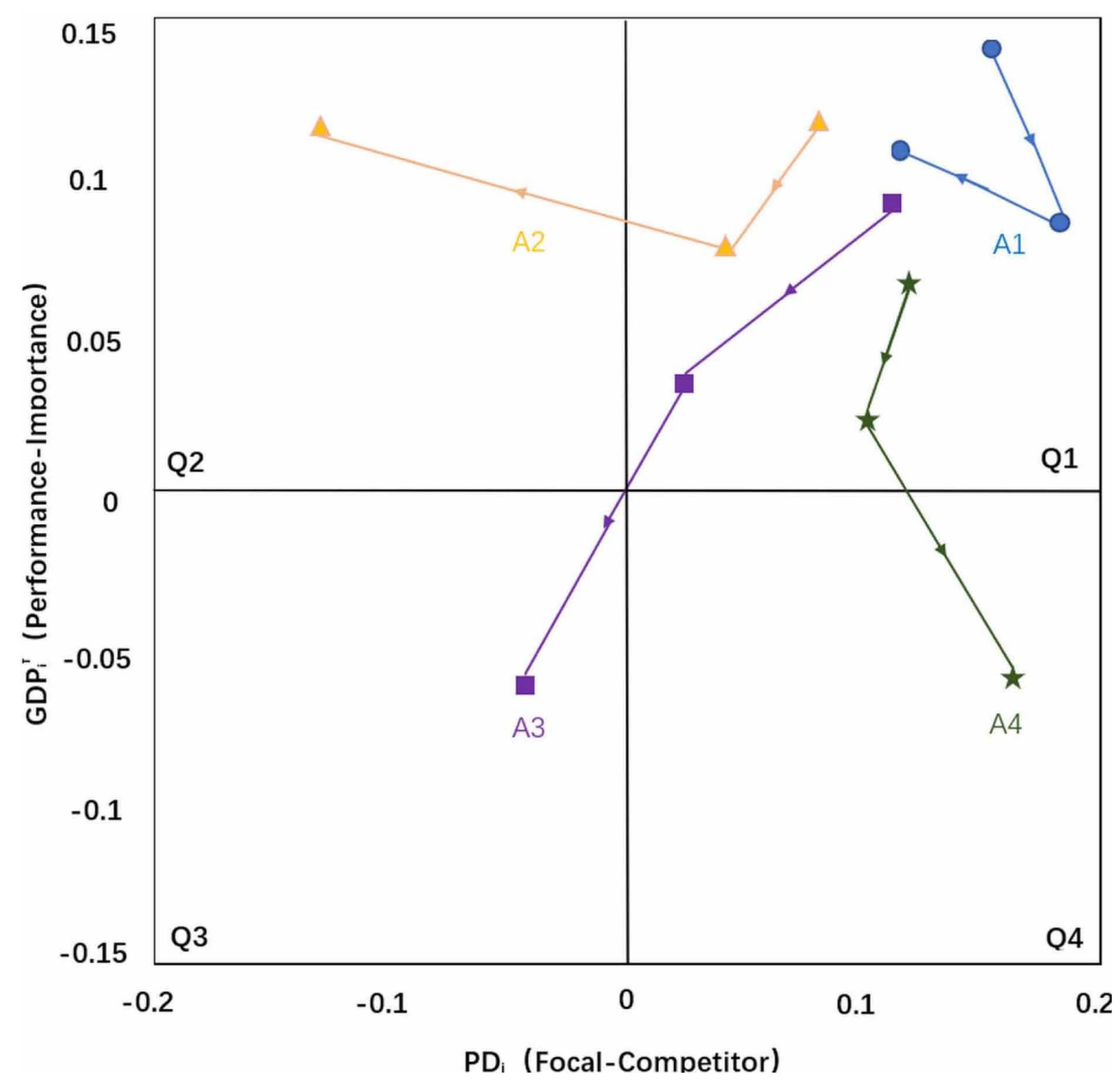

hotel was taken as the y-axis, and the time variable was expressed as the points and directions of hotel customer satisfaction indices in the coordinate system.

As shown in Figure 3, in the first quadrant (Q1), the performance of the focal hotel surpasses the customer expectation (GAP $>0$ ) and that of the competitor performance ( $\mathrm{PD}>0$ ), that is, the focal hotel has solid competitive advantage. In this case, the focal hotel should maintain its performance.

In the second quadrant $(\mathrm{Q} 2)$, the performance of the focal hotel surpasses the customer expectation $(\mathrm{GAP}>0)$ but lags behind that of the competitor $(\mathrm{GAP}<0)$, that is, the focal hotel faces head-to-head competition with the competitor. In this case, the customer selection hinges on index difference between hotels, rather than the prominence of indices; the best practice for the focal hotel is to catch up with and even surpass the performance of its competitor through benchmarking management.

In the third quadrant (Q3), the performance of the focal hotel falls short of the customer expectation $(\mathrm{GAP}<0)$ and that of the competitor $(\mathrm{GP}<0)$, that is, the focal hotel is weak in hotel customer satisfaction. In this case, the focal hotel needs to take urgent actions to improve the high marginal income of inputs. 
In the fourth quadrant $(\mathrm{Q} 4)$, the performance of the focal hotel falls short of the customer expectation $(\mathrm{GAP}<0)$, but surpasses that of the competitor $(\mathrm{GP}>0)$, that is, the focal hotel has null advantage for the unreachability of customer expectation. In this case, the focal hotel should lower the priority of inputs to this category.

The calculation formulas of the DIPCA are as follows (Bi et al.,2019):

$$
G A P_{i}^{f t}=\overline{P e r_{i}^{f t}}-\overline{I m p_{i}^{f t}}(i=1,2,3 \ldots I, t=1,2,3 \ldots T)
$$

$$
\overline{\operatorname{Per}_{i}^{f t}}=\frac{P e r_{i}^{f t}}{\sum_{i=1}^{I} \operatorname{Per}_{i}^{f t}}(i=1,2,3 \ldots I, t=1,2,3 \ldots T)
$$

$$
\overline{\operatorname{Im} p_{i}^{f t}}=\frac{I m p_{i}^{f t}}{\sum_{i=1}^{I} \operatorname{Im} p_{i}^{f t}}(i=1,2,3 \ldots I, t=1,2,3 \ldots T)
$$

$$
P D_{i}^{t}=\operatorname{Per}_{i}^{f t}-\operatorname{Per}_{i}^{c t}(i=1,2,3 \ldots I, t=1,2,3 \ldots T)
$$

The DIPCA model has several typical modes of change (Bi et al.,2019), which are explained here with the example in Figure 3.

(1) Both GAP and PD change in a certain interval, e.g., index A1 remains in Q1. This means, despite the elapse of time, there is no significant change to the PD between focal hotel and competitor in hotel customer satisfaction and the GAP between the perceived performance and customer expectation of the focal hotel. In this case, the focal hotel should stick to the original management strategy and maintain its performance.

(2) There is a significant change in PD, but not in GAP, e.g., index A2 shifts from Q1 to Q2. This means the performance of the focal hotel measured by the index has been declining and is lower than that of the competitor, although the performance stays above customer expectation. In this case, the focal hotel must allocate more resources to improve the performance of the index, such as to catch up with the competitor in this respect.

(3) There are significant changes to both GAP and PD, e.g., index A3 shifts from Q1 to Q3. This means the performance of the focal hotel measured by the index has plunged over time, and falls short of that of the competitor and customer expectation. In this case, the focal hotel should take urgent actions to improve the performance of the index.

(4) There is a significant change in GAP, but not in PD e.g., index A4 shifts from Q1 to Q4. This means the performance of the focal hotel measured by the index falls short of customer expectation, while surpassing that of the competitor. In this case, the solid competitive advantage of the focal hotel becomes null advantage. 
Other changes are variations or superpositions of these four modes. The DIPCA reveals whether hotel performance in different periods has reached customer expectation, and whether it has reached the level of the competitors, laying a solid basis for designing scientific management strategies.

\section{CASE STUDY}

\subsection{Case Selection and Corpus Processing}

Two representative hotels in downtown Chongqing, southwestern China, were selected for case study. Hotel A was taken as the focal hotel, and Hotel B as the competitor. Both of them are five-star business hotels. Located in the core of two business districts, the two hotels are only $10 \mathrm{~km}$ away, facing heated competition with each other.

The review corpus of the two hotels from January 2017 to December 2019 were obtained from ctrip.com, and preprocessed into 4,204 reviews and 3,674 reviews, respectively.

\subsection{Index System Construction}

By formula (1), the boundary value between high- and low-frequency words was calculated as $n=81$. Hence, the words whose frequency is no smaller than 81 were taken as high-frequency words. Through the six-step method mentioned above, nine categories of topics were obtained. The high-frequency words were allocated to different categories of topics, serving as topic keywords. On this basis, the phrases were selected from the reviews to form the index system of hotel customer satisfaction (Table 2).

Table 2. The index system of hotel customer satisfaction

\begin{tabular}{|c|c|c|}
\hline Topics & Topic keywords & Example phrases \\
\hline Housekeeping category & $\begin{array}{l}\text { Guest room, Room, Bed, Toilet, Butler, Suite, } \\
\text { River view room, Air conditioning }\end{array}$ & $\begin{array}{l}\text { The guest rooms are clean. } \\
\text { The bed is particularly comfortable. } \\
\text { The river view room is really beautiful. }\end{array}$ \\
\hline F\&B category & Catering, Breakfast, Taste, Variety, Dining hall & $\begin{array}{l}\text { The breakfast is mediocre. } \\
\text { The hot pot tastes good. } \\
\text { The dining hall serves food of good quality. }\end{array}$ \\
\hline Facility category & $\begin{array}{l}\text { Facility, Parking lot, Equipment, Swimming } \\
\text { pool, Decoration, Hardware }\end{array}$ & $\begin{array}{l}\text { The facilities are a bit old. } \\
\text { The signs in the underground parking lot are not clear. } \\
\text { The pool is clean and odor-free. }\end{array}$ \\
\hline Service category & $\begin{array}{l}\text { Service, Front desk, Manager, Waiter, Service } \\
\text { attitude, Attitude, Parking, Staff, Concierge, } \\
\text { Check-out }\end{array}$ & $\begin{array}{l}\text { The service is poor. } \\
\text { The front desk is cold in manner. } \\
\text { The concierge helped with luggage. }\end{array}$ \\
\hline Price category & $\begin{array}{l}\text { Price, Cost performance, Upgrade, Free, Cost, } \\
\text { Deserve }\end{array}$ & $\begin{array}{l}\text { The price is high. } \\
\text { The cost performance is good. } \\
\text { The parking is free. }\end{array}$ \\
\hline $\begin{array}{l}\text { Transportation } \\
\text { category }\end{array}$ & Traffic, Location, Center, Section, Place & $\begin{array}{l}\text { The traffic is convenient. } \\
\text { The location is good. } \\
\text { The hotel is in a prosperous area. }\end{array}$ \\
\hline Environment category & $\begin{array}{l}\text { Environment, Sanitation, Night view, River } \\
\text { view, Scenery, Landscape }\end{array}$ & $\begin{array}{l}\text { The environment is nice. } \\
\text { The night view is beautiful. } \\
\text { The sanitation is far from satisfactory. }\end{array}$ \\
\hline Supporting category & $\begin{array}{l}\text { Shopping, Eating, Food, Pedestrian street, } \\
\text { Guanyinqiao, Nanbin Road }\end{array}$ & $\begin{array}{l}\text { It is convenient to shop around. } \\
\text { There are lots of food nearby. } \\
\text { The hotel is close to Guanyinqiao Pedestrian Street. }\end{array}$ \\
\hline $\begin{array}{l}\text { Comprehensive } \\
\text { category }\end{array}$ & Overall, Feeling, Whole, Experience & $\begin{array}{l}\text { I am satisfied overall. } \\
\text { I did not feel at home. } \\
\text { It is a very comfortable experience. }\end{array}$ \\
\hline
\end{tabular}


Specifically, the indices of housekeeping and food \& beverage $(F \& B)$ categories cover the facilities and products/services used or provided in guest rooms and the dining hall. The indices of facility and service categories cover the facilities and products/services used or provided in the public areas of the hotel. The indices of price category cover the feelings about price, cost, fee, and value of all customers in and outside the hotel. The indices of transportation category cover the traffic conditions and geographic location of the hotel. The indices of the environment category cover the internal public environment except the dining hall, guest rooms and the external environment. The indices of the supporting category cover the leisure and entertainment, catering, and shopping elements in the external environment. The indices of the comprehensive category, designed based on the ACSI, cover the overall evaluations and feelings related to hotel customer satisfaction, including antecedent variables like customer expectation, perceived quality, and perceived value, satisfaction variables, and outcome variables like customer loyalty and customer complaint.

Our index system is basically consistent with the previous index systems for hotel customer satisfaction, which take online reviews as the data source. The indices of housekeeping, service, price, and transportation were mentioned by Li et al. (2013), Xu \& Li (2016), and Pacheco (2017). The indices of F\&B were adopted by Li et al. (2013), and Xu \& Li (2016). The indices of facility were discussed in Li et al. (2013), and Pacheco (2017). The indices of environment were studied in Pacheco (2017). The indices of supporting and comprehensive categories were not mentioned by these scholars (Table 1).

In previous studies, the supporting indices in the surroundings of the hotel are deemed as uncontrollable external factors that need not to be considered in the evaluation of customer satisfaction. However, the surrounding supporting indices could be changed by the site selection and facility construction of the hotel, making these indices partly controllable. Thus, it is important to take account of these indices in the measurement and evaluation of hotel customer satisfaction.

The index system of customer satisfaction is a whole. The antecedent and outcomes must be considered, in addition to its own attributes. That is why the indices of comprehensive category were added to the index system, revealing the impact of comprehensive indices on the measurement and evaluation. Compared with existing index systems, our index system is comprehensive, thanks to the innovative inclusion of supporting and comprehensive indices.

According to the above topic categories and topic keywords, a total of 19,132 phrases was decomposed from the review corpus of hotels $\mathrm{A}$ and $\mathrm{B}$, using period, question mark, exclamation mark, spacing, tilde, ellipsis, and number sign as the demarcation points. Then, 15,983 subjective phrases were selected by the Navis Bayes classifier, including 8,999 phrases of Hotel A and 6,984 phrases of Hotel B.

\subsection{Measurement of Hotel Customer Satisfaction}

The effects of the number of paradigm words on emotional polarity and intensity were tested through experiments. The paradigm words were selected from the sets of commendatory and derogatory paradigm words and high-frequency words in previous studies on the Chinese language, provided that they are representative, inambiguous, and polarized in emotion. The best effects were observed, when there were 30 pairs of paradigm words. Hence, the 30 pairs of paradigm words in Table 3 were selected for subsequent sentiment analysis.

Based on the index system, the SOVs of each index in different seasons of hotels A and B were obtained from formulas (2)- (6). Table 4 records the mean SOVs and weights of indices in each category of Hotel A in the first season of 2017. It can be seen that the mean hotel customer satisfaction with Hotel A in that season was 0.7009 .

The mean hotel customer satisfactions of that hotel in other seasons were calculated similarly. As shown in Table 5, the hotel customer satisfaction of Hotel A was relatively good, without severe fluctuations. Then, the mean SOV and weight of each topic category of Hotel A were obtained through sentiment analysis. Similarly, the mean hotel customer satisfaction in each topic category and the 
Table 3. The 30 pairs of paradigm words

\begin{tabular}{|c|c|c|c|c|c|}
\hline \multicolumn{6}{|c|}{ Commendatory paradigm words } \\
\hline Excellent & Like & Well-pleasing & Beautiful & Complete & Comfortable \\
\hline Praise & Clean & Recommend & Nice & Joyful & Perfect \\
\hline Quick & Satisfying & Impartial & Civilized & Safety & Beautiful \\
\hline Gorgeous & Happiness & Positive evaluation & Inexpensive & Well & Enthusiastic \\
\hline Happy & Superior & Easy & Healthy & Outstanding & Bargain \\
\hline \multicolumn{6}{|c|}{ Derogatory paradigm words } \\
\hline Messy & Awkward & Disappointed & Ugly & Expensive & Lazy \\
\hline Inferior & Dirty & Lying & Treacherous & Scurvy & Terrible \\
\hline $\mathrm{Bad}$ & Ragged & Indignant & Violence & Silly & Good-for-nothing \\
\hline Error & Crowded & Hapless & Ungated & Tricked & Tedious \\
\hline Sad & Waste & Insufficient & Harmful & Rubbish & Despicable \\
\hline
\end{tabular}

Table 4. The mean SOVs, weights of indices and mean hotel customer satisfaction of Hotel A in the first season of 2017

\begin{tabular}{|c|c|c|c|}
\hline Index Categories & Mean SOVs & Weights & $\begin{array}{l}\text { Mean hotel customer } \\
\text { satisfaction }\end{array}$ \\
\hline Housekeeping & 0.7027 & 0.1133 & \multirow{9}{*}{0.7009} \\
\hline$F \& B$ & 0.6415 & 0.0234 & \\
\hline Service & 0.7445 & 0.3633 & \\
\hline Facility & 0.4805 & 0.0625 & \\
\hline Environment & 0.7397 & 0.1016 & \\
\hline Supporting & 0.6298 & 0.0781 & \\
\hline Transportation & 0.7751 & 0.1523 & \\
\hline Price & 0.4903 & 0.0605 & \\
\hline Comprehensive & 0.7488 & 0.0449 & \\
\hline
\end{tabular}

Table 5. The mean customer satisfactions of Hotel A in different seasons

\begin{tabular}{|l|l|l|l|}
\hline Seasons & Mean SOVs & Season & Mean SOVs \\
\hline $2017(01)$ & 0.7009 & $2018(03)$ & 0.7592 \\
\hline $2017(02)$ & 0.7002 & $2018(04)$ & 0.6917 \\
\hline $2017(03)$ & 0.6446 & $2019(01)$ & 0.7046 \\
\hline $2017(04)$ & 0.6935 & $2019(02)$ & 0.6626 \\
\hline $2018(01)$ & 0.6866 & $2019(03)$ & 0.6640 \\
\hline $2018(02)$ & 0.7437 & $2019(04)$ & 0.6935 \\
\hline
\end{tabular}


Table 6. The mean hotel customer satisfaction of each topic category of Hotel A

\begin{tabular}{|c|c|c|c|}
\hline Index Category & $\begin{array}{l}\text { Mean hotel customer } \\
\text { satisfaction }\end{array}$ & Weights & $\begin{array}{l}\text { Mean hotel customer } \\
\text { satisfaction of all categories }\end{array}$ \\
\hline Housekeeping & 0.6486 & 0.1103 & \multirow{9}{*}{0.6955} \\
\hline $\mathrm{F} \& \mathrm{~B}$ & 0.6086 & 0.0391 & \\
\hline Service & 0.7408 & 0.4816 & \\
\hline Facility & 0.4638 & 0.0490 & \\
\hline Environment & 0.6940 & 0.0677 & \\
\hline Supporting & 0.6618 & 0.0675 & \\
\hline Transportation & 0.7399 & 0.1199 & \\
\hline Price & 0.5744 & 0.0387 & \\
\hline Comprehensive & 0.6890 & 0.0262 & \\
\hline
\end{tabular}

overall hotel customer satisfaction were calculated. As shown in Table 6, Hotel A had relatively good overall satisfaction (0.6955).

According to the effect test of sentiment analysis (Part 3.4.1), the samples were selected evenly from the nine topic categories. A total of 900 phrases were collected, including 50 random phrases in each topic of each of the two hotels. The phrases were subject to emotional intensity test and manual tagging of emotional intensities. All values were normalized to the interval of $[0,1]$. The allowable error range was defined as 0.1 and 0.2 . The results show that our algorithm achieved an accuracy of $71 \%$ and $93 \%$ under the allowable error ranges of 0.1 and 0.2 , respectively. This fully demonstrates the good effect of sentiment analysis.

\subsection{The DIPCA of Hotel Customer Satisfaction}

Taking Hotel A as the focal hotel and Hotel B as the competitor, the evaluation results of the two hotels were plotted in to the coordinate system of the DIPCA, where the midpoints of the $\mathrm{x}$ and $\mathrm{y}$-axes are both zeros. Each category of indices was analyzed in details (Figure 4) to reveal the dynamic changes of hotel customer satisfaction and competition between the two hotels. For convenience, 2017, 2018, and 2019 are referred to as the early phase, middle phase, and late phase, respectively.

As shown in Figure 4 (a), the indices of housekeeping category had counterclockwise rotation before clockwise rotation about the x-axis. Overall, the performance of Hotel A was distributed around the customer expectation and the performance of the competitor. In most periods, Hotel A failed to achieve the customer expectation, but outperform its competitor. The advantage is null, especially in the late phase, where it entered the Q4 twice. Thus, it is necessary to lower the priority of inputs to this category.

As shown in Figure 4 (b), the indices of F\&B category mainly shifted from Q1 and Q2 to Q3 and Q4. The performance measured by these indices was declining over time. During the late phase, the PD value rested near the midpoint $(0)$ of the $\mathrm{x}$-axis, indicating that the recent performance of Hotel A fell short of customer expectation $(\mathrm{GAP}<0)$ and lost the edge over the performance of its competitor. Hotel A must take urgent measures to improve its performance, and reach the customer expectation, while keeping the edge over its competitor.

As shown in Figure 4 (c), the indices of service category basically moved from Q1 to Q3 and Q4, before returning to Q1. In most periods, the performance measured by the indices of service category surpassed that of the competitor, but failed to reach customer expectation in four periods of the early and middle phases (i.e., within Q4). In the seven periods of the initial and later phases, 
Journal of Organizational and End User Computing Volume 33 • Issue 6 • November-December 2021

Figure 4. The DIPCA plot of hotel customer satisfactions of the two hotels

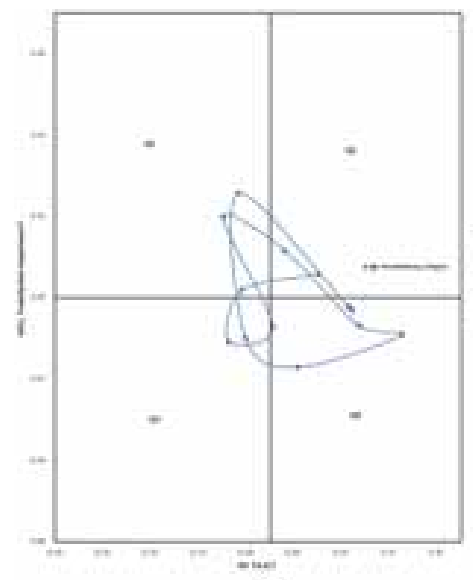

(a)

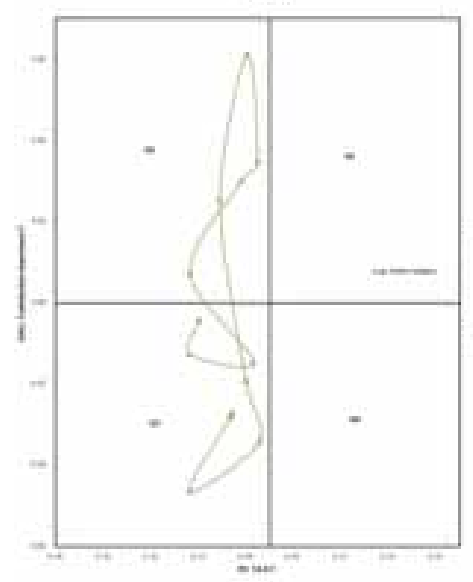

(d)

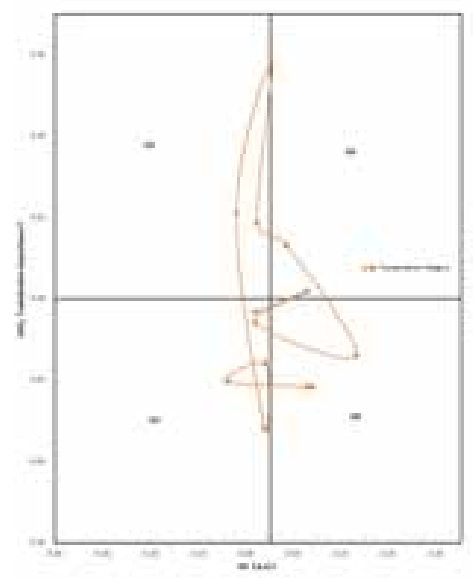

(g)

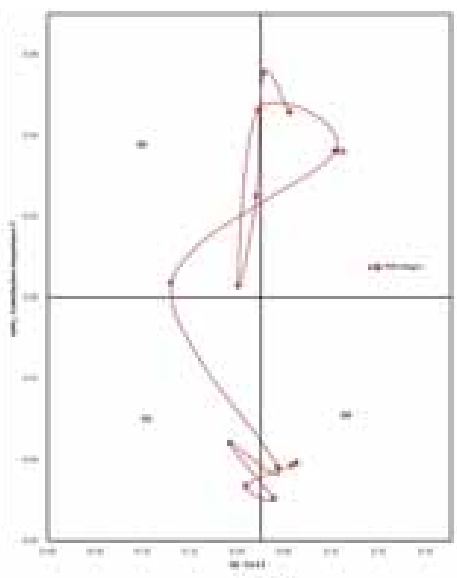

(b)

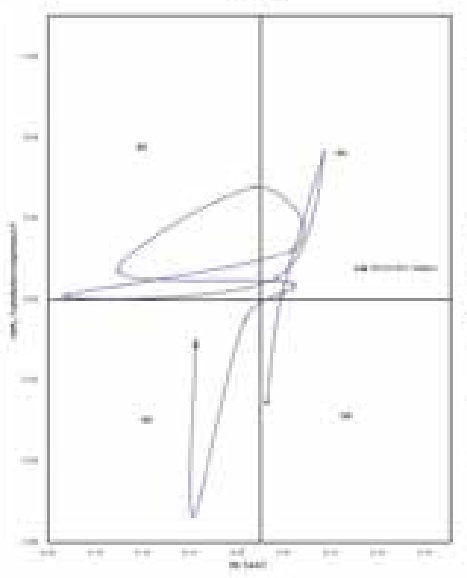

(e)

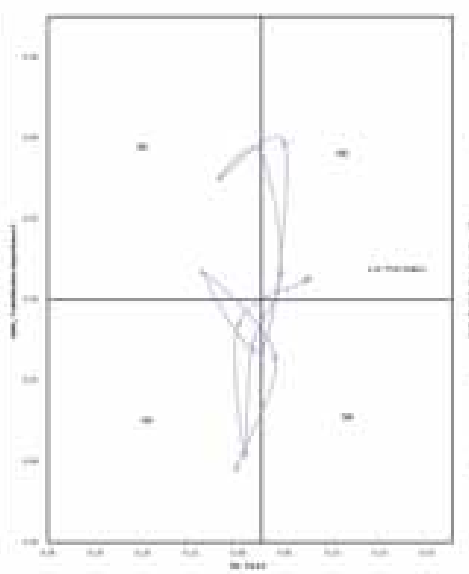

(h)

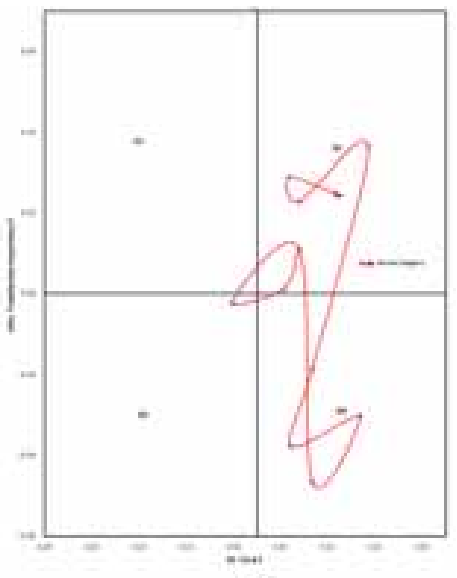

(c)

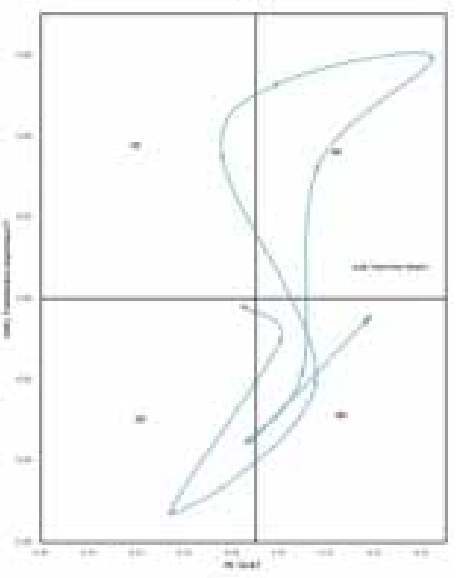

(f)

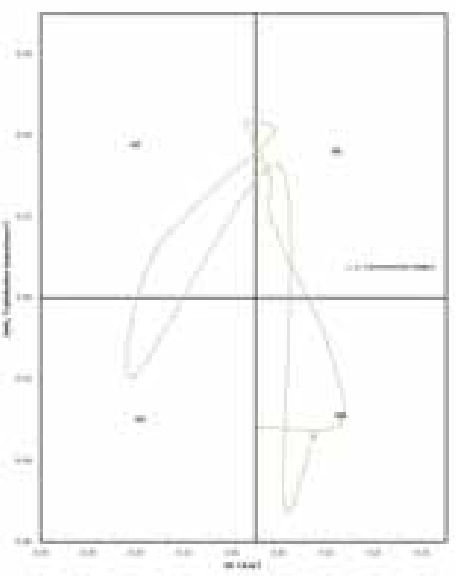

(i)

19 
the performance surpassed customer expectation (i.e., within Q1). Further inputs to this category are needed to maintain the competitive advantage.

As shown in Figure 4 (d), the indices of facility category generally moved from Q3 to Q2, before returning to Q3. For these indices, the GAP went through a process of declining-rising-decliningrising, while the PD remained negative, indicating that Hotel A performed poorer than Hotel B. As a result, in the middle phase, Hotel A's performance surpassed customer expectation (i.e., in Q2); the hotel should adopt benchmarking management to catch up with its competitor in performance. In the early and late phases, when its performance fell short of customer expectation (i.e., in Q3), Hotel A must take urgent actions to improve its performance.

As shown in Figure 4 (e), the performance measured by the indices of environment category reached and exceeded customer expectation in most periods, but fell below customer expectation in recent periods, showing some oscillations. Compared with that of the competitor, the performance of the focal hotel exhibited a declining trend. The performance gap peaked at a high level of 0.4141 , belonging to the interval of $[0,1]$. In the late phases, the indices moved from Q1 to Q3. As a result, Hotel A should take urgent actions to improve the performance measured by these indices.

As shown in Figure 4 (f), the performance measured by the indices of supporting category reached and surpassed the performance of the competitor in most periods, but only exceeded customer expectation for a short period of time. Thus, most index points concentrated in or near Q4. In the early phase, the said indices fell in Q1 and Q4; in the middle phase, the indices developed well, entering or approximating Q1; in the late phase, the indices either fell in or near Q4, turning the advantage of the focal hotel useless. Hence, Hotel A should lower the priority of inputs to this category.

As shown in Figure $4(\mathrm{~g})$, In most periods, the performance measured by the indices of transportation category did not clearly outshine that of its competitor. More than half of the indices were clustered in or near Q4. In the early phase, the performance oscillated significantly, with most of the indices in or near Q4. In the middle phase, the indices developed well, gathering in or near Q1. In the first three seasons of the late phase, these indices fell in Q3, calling for urgent actions to input more into this category; in the last season, the performance fell near or within Q1, calling for continued inputs to maintain the edge.

As shown in Figure 4 (h), the performance measured by half of the indices of price category surpassed customer expectation, while that measured by less than half of price indices outshined the competitor's performance. Overall, the price indices were virtually evenly distributed across the four quadrants, exhibiting an oscillation. In the early phase, the indices fell in or near Q4; in the middle phase, the indices fell in or near Q1; in the late phase, the indices fell in or near Q3. In five periods, the performance fell near or within Q3, calling for urgent actions to input more into this category; in four periods, the performance fell near or within Q1, calling for continued inputs to maintain the edge.

As shown in Figure 4 (i), the indices of comprehensive category oscillated complicatedly between Q4-Q1-Q2-Q3-Q1-Q4, but mainly lay in Q4 and Q1. From the early phase, these indices mostly belonged to $\mathrm{Q} 4$, that is, they are useless indices of competitive edge. Specifically, the indices entered Q1, the quadrant of solid advantage, in the fourth season. In the middle phase, most of these indices belonged to Q1. Specifically, the indices entered Q2, the quadrant of positive competition, in the fourth season. In the late phase, the indices fluctuated very significantly, migrating between three quadrants: Q3-Q1-Q4. In the last two seasons, they arrived in Q4, the quadrant of useless competitive edge. In general, this category of indices mainly appeared in Q4 and Q1. In most periods, Hotel A outperformed its competitor. However, when the perceived performance surpassed customer expectation (i.e., within Q1), Hotel A should strive to maintain its performance; when the perceived performance fell short of customer expectation (i.e., within Q4 as in the last two seasons), Hotel A should lower the priority of inputs to this category. 


\section{CONCLUSION AND DISCUSSION}

\subsection{Conclusion}

Based on sentiment analysis of online reviews, this paper puts forward a dynamic framework for measuring and evaluating hotel customer satisfaction. The framework is found applicable to the measurement and evaluation of hotel customer satisfaction. Starting from online reviews, our framework and its methods can objectively and truthfully reflect the dynamic changes in the overall and specifics of hotel customer satisfaction, and provide a theoretical support to the management and optimization of hotel customer satisfaction. The main conclusions are as follows:

(1) This paper mainly relies on statistical feature-based method to extract the topics of hotel customer satisfaction. Specifically, the topic keywords were extracted using high-frequency word statistics, word $2 \mathrm{vec}$ model, synonym forest, and word frequency co-occurrence matrix. Referring to relevant theories, the main categories of topics were determined by word frequency co-occurrence matrix and LDA topic clustering. On this basis, an index system was set up for hotel customer satisfaction, involving a topic layer, an index layer, and a phrase layer.

(2) Besides, the CTSSSO algorithm was developed to analyze the sentiment of the phrases in online reviews. Based on the weights of the indices, the authors calculated the hotel customer satisfactions with each index in different periods, the mean hotel customer satisfaction of all indices in each period, the mean hotel customer satisfaction of each topic, and the overall hotel customer satisfaction of all indices in different periods.

(3) In addition, the hotel customer satisfaction was dynamically evaluated through the DIPCA, which judges whether the hotel customer satisfaction of the focal hotel reaches the customer expectation and that of the competitor. Drawing on the different modes of change in the DIPCA, the hotel customer satisfaction of actual hotels was discussed in details, and feasible management strategies were presented to improve the satisfaction level.

\subsection{Limitations and Future Research}

There are several limitations of this research. First, it is assumed that, with the elapse of time, the hotel customer satisfaction does not change in dimensions, but in the weight and SOV of each dimension. This assumption does not necessarily hold in real-world scenarios. If the internal and external conditions remain the same, the dimensions of customer demand, i.e., those of hotel customer satisfaction, will not change significantly in the short term. However, dimensional changes are inevitable if these conditions vary greatly or in the long run. The future research could analyze the dimensional changes and index systems of hotel customer satisfaction through or within different periods, when internal and external conditions remain basically unchanged, and explore the variations in the dimensions of customer demand and the index system of hotel customer satisfaction under major public health events like COVID-19.

Second, the sentiment analysis in this research lacks in the following aspects: (1) The simple differentiation between subjective and objective phrases has not been proved with abundant corpus; (2) Only single-topic phrases (multi-topic phrases are converted into single-topic phrases, retaining the topic with the highest SOV only) are evaluated; (3) Only the few most common internal grammatical 
structures of online hotel reviews are contained in the phrases; (4) The center term and its adverbs of each phrase were taken as the basis for evaluation, failing to consider the connections between phrases.

To solve the defects in sentiment analysis, the future research will deal with the following two aspects: (1) improve the classification between subjective and objective phrases, drawing on the features of review phrases with attribute-level granularity, as well as their semantic and syntax features. (2) summarize the common grammatical and syntactic structures in hotel reviews and their phrases, and consider the superimposition between the internal topics of the phrases, as well as the connections between the phrases (e.g., dependence syntax), thereby optimizing the effect of sentiment analysis.

\section{ACKNOWLEDGMENT}

This work was supported by Major Advisory Decision-Making Research Project of Chongqing Municipal Government (Grant No.2017-ZB06), Science and Technology Research Project of Chongqing Municipal Education Commission (Grant No.KJ1600331), Chongqing Social Science Planning Project (Grant No.2014YBSH045). 


\section{REFERENCES}

Akhtar, M. S., Ghosal, D., Ekbal, A., Bhattacharyya, P., \& Kurohashi, S. (2018). A multi-task ensemble framework for emotion, sentiment and intensity prediction. Retrieved from https://arxiv.org/abs/1808.01216v1

Akhtar, N., Zubair, N., Kumar, A., \& Ahmad, T. (2017). Aspect based sentiment oriented summarization of hotel reviews. Procedia Computer Science, 115, 563-571. doi:10.1016/j.procs.2017.09.115

Aklimawati, L., \& Hartatri, F. S. (2019). Assessment of Service Quality Using Weighted SERVPERF Approach. Pelita Perkebunan, 35(1), 70-84. doi:10.22302/iccri.jur.pelitaperkebunan.v35i1.352

Al, R., \& Wahidul, M. (2020). Assessing customer demand and customer satisfaction through social and environmental practices in the hotel sector of bangladesh. Geo Journal of Tourism and Geosites, 30(2), 843-851. doi:10.30892/gtg.302sp109-513

Albayrak, T., \& Caber, M. (2015). Prioritisation of the hotel attributes according to their influence on satisfaction: A comparison of two techniques. Tourism Management, 46(2), 43-50. doi:10.1016/j.tourman.2014.06.009

Amin, M., Yahya, Z., Ismayatim, W. F. A., Nasharuddin, S. Z., \& Kassim, E. (2013). Service quality dimension and customer satisfaction: An empirical study in the Malaysian hotel industry. Services Marketing Quarterly, 34(2), 115-125. doi:10.1080/15332969.2013.770665

Archak, N., Ghose, A., \& Ipeirotis, P. G. (2011). Deriving the pricing power of product features by mining consumer reviews. Social Science Electronic Publishing, 57(8), 1485-1509. doi:10.1287/mnsc.1110.1370

Assaf, A. G., Josiassen, A., Cvelbar, L. K., \& Woo, L. (2015). The Effects of Customer Voice on Hotel Performance. International Journal of Hospitality Management, 44, 77-83. doi:10.1016/j.ijhm.2014.09.009

Babi-Hodovi, V., Arslanagi-Kalajdi, M., Banda, A., \& Sivac, A. (2019). IPA and SERVPERF quality conceptualisations and their role in hotel services satisfaction. Tourism and Hospitality Management, 25(1), 1-17. doi:10.20867/thm.25.1.4

Beheshtinia, M. A., \& Azad, M. F. (2019). A fuzzy QFD approach using SERVQUAL and kano models under budget constraint for hotel services. Total Quality Management \& Business Excellence, 30(2), 1-23. doi:10.10 80/14783363.2017.1340830

Bi, J. W., Liu, Y., Fan, Z. P., \& Zhang, J. (2019). Wisdom of crowds: Conducting importance-performance analysis (IPA) through online reviews. Tourism Management, 70(2), 460-478. doi:10.1016/j.tourman.2018.09.010

Blei, D. M., Ng, A. Y., \& Jordan, M. (2003). Latent Dirichlet Allocation. Journal of Machine Learning Research, 3(7), 993-1022. doi:10.1162/jmlr.2003.3.4-5.993

Cai, G., Hong, Y., Xu, L., Gao, W., Wang, K., \& Chi, X. (2021). An Evaluation of Green Ryokans through a Tourism Accommodation Survey and Customer-Satisfaction-Related CASBEE-IPA after COVID-19 Pandemic. Sustainability, 13(1), 145. doi:10.3390/su13010145

Chan, K. Y., Kwong, C. K., \& Kremer, G. E. (2020). Predicting customer satisfaction based on online reviews and hybrid ensemble genetic programming algorithms. Engineering Applications of Artificial Intelligence, 95, 1-13. doi:10.1016/j.engappai.2020.103902

Chang, V., Liu, L., Xu, Q., Li, T., \& Hsu, C.-H. (2020). An improved model for sentiment analysis on luxury hotel review. Expert Systems: International Journal of Knowledge Engineering and Neural Networks. Advance online publication. doi:10.1111/exsy.12580

Che, W., Li, Z., \& Liu, T. (2010). LTP: A Chinese Language Technology Platform. In Proceedings of the Coling 2010. Demonstrations.

Chen, J., Becken, S., \& Stantic, B. (2019). Lexicon based Chinese language sentiment analysis method. Computer Science and Information Systems, 16(2), 639-655. doi:10.2298/CSIS181015013C

China Hospitality Association. (2019). Online word of mouth report of Chinese accommodation Industry market in 2019. Retrieved from http://www.chinahotel.org.cn/ChoiceOSP/upload/file/20190408/71741554707046474.pdf

Chu, R. (2002). Stated-importance versus derived-importance customer satisfaction measurement. Journal of Services Marketing, 16(4), 285-301. doi:10.1108/08876040210433202 
Cronin, J. J. Jr, \& Taylor, S. A. (1992). Measuring Service Quality: A Reexamination and Extension. Journal of Marketing, 56(3), 55-68. doi:10.1177/002224299205600304

Cronin, J. J. Jr, \& Taylor, S. A. (1994). SERVPERF Versus SERVQUAL: Reconciling Performance Based and Perception-Minus-Expectations Measurement of Service Quality. Journal of Marketing, 58(1), $125-131$. doi:10.1177/002224299405800110

Davras, Ö., \& Caber, M. (2019). Analysis of hotel services by their symmetric and asymmetric effects on overall customer satisfaction: A comparison of market segments. International Journal of Hospitality Management, 81, 83-93. doi:10.1016/j.ijhm.2019.03.003

Decker, R., \& Trusov, M. (2010). Estimating aggregate consumer preferences from online product reviews. International Journal of Research in Marketing, 27(4), 293-307. doi:10.1016/j.ijresmar.2010.09.001

Demir, Y. E., Durmaz, S., Elbir, A., Sigirci, I. O., \& Diri, B. (2020). Sentiment Analysis for Hotel Attributes from Online Reviews. In 2020 Innovations in Intelligent Systems and Applications Conference (ASYU), Istanbul, Turkey.

Deng, W. J., Yeh, M. L., \& Sung, M. L. (2013). A customer satisfaction index model for international tourist hotels: Integrating consumption emotions into the American Customer Satisfaction Index. International Journal of Hospitality Management, 35, 133-140. doi:10.1016/j.ijhm.2013.05.010

Dong, Z. D., \& Dong, Q. (2003). HowNet-a hybrid language and knowledge resource. In International Conference on Natural Language Processing and Knowledge Engineering. IEEE. doi:10.1109/NLPKE.2003.1276017

Dong, Z. D., \& Dong, Q. (2013). HowNet Knowledge Database. Retrieved from http://www.keenage.com

Donohue, J. C. (1973). Understanding scientific literatures: A Bibliometric Approach. The MIT Press.

Duan, W. J., Cao, Q. Yu. Y., \& Levy, S. (2013). Mining Online User-Generated Content: Using Sentiment Analysis Technique to Study Hotel Service Quality. In Hawaii International Conference on System Sciences. IEEE. doi:10.1109/HICSS.2013.400

Elsaid, M. M., Hussein, M. E., \& Hassan, H. M. (2018). A generic lexicon-based framework for sentiment analysis. International Journal of Computers and Applications, 42(3), 1-11.

Eygu, H., \& Gulluce, A. C. (2017). Determination of customer satisfaction in conservative concept hotels by ordinal logistic regression analysis. Journal of Financial Risk Management, 6(3), 269-284. doi:10.4236/ jfrm.2017.63020

Fang, B., Ye, Q., Kucukusta, D., \& Law, R. (2016). Analysis of the perceived value of online tourism reviews: Influence of readability and reviewer characteristics. Tourism Management, 52, 498-506. doi:10.1016/j. tourman.2015.07.018

Ferrari, P. A., \& Manzi, G. (2010). Nonlinear principal component analysis as a tool for the evaluation of customer satisfaction. Quality Technology \& Quantitative Management, 7(2), 117-132. doi:10.1080/1684370 3.2010 .11673223

Fornell, C., Johnson, M. D., Anderson, E. W., Cha, J., \& Bryant, B. E. (1996). The American customer satisfaction index: Nature, purpose, and findings. Journal of Marketing, 60(4), 7-19. doi:10.1177/002224299606000403

Freitas, L. A., \& Vieira, R. (2013). Ontology based feature level opinion mining for portuguese reviews. In 22nd International World Wide Web Conference - Doctoral Consortium. ACM. doi:10.1145/2487788.2487944

Fu, X., Liu, W., Xu, Y., \& Cui, L. (2017). Combine HowNet Lexicon to Train Phrase Recursive Autoencoder for Sentence-Level Sentiment Analysis. Neurocomputing, 241(7), 18-27. 10.1016/j.neucom.2017.01.079

Gilbert, D., \& Horsnell, S. (1998). Customer Satisfaction Measurement Practice in United Kingdom Hotels. Journal of Hospitality \& Tourism Research (Washington, D.C.), 22(4), 450-464. doi:10.1177/109634809802200408

Groves, R. M. (2006). Nonresponse rates and nonresponse bias in household surveys. Public Opinion Quarterly, 70(5), 646-675. doi:10.1093/poq/nf1033 
Guo, Y., Barnes, S. J., \& Jia, Q. (2017). Mining Meaning from Online Ratings and Reviews: Tourist Satisfaction Analysis Using Latent Dirichlet Allocation. Tourism Management, 59, 467-483. doi:10.1016/j. tourman.2016.09.009

Gupta, P., \& Srivastava, R. (2011). Analysis of customer satisfaction in hotel service quality using Analytic Hierarchy Process (AHP). Academic Press.

HIT-SCIR. (2012). HIT IR-Lab Tongyici Cilin (Extended). Retrieved from http://ir.hit.edu.cn

Ho, L. H., Peng, T. F., Feng, S. Y., \& Yen, T. M. (2013). Integration of Kano's Model and SERVQUAL for enhancing Standard Hotel Customer Satisfaction. African Journal of Business Management, 7(23), 2257-2265. doi:10.5897/AJBM11.1421

Hu, M. Q., \& Liu, B. (2004). Mining and summarizing customer reviews. In Proceedings of the Tenth ACM SIGKDD International Conference on Knowledge Discovery and Data Mining. ACM.

Hu, N., Koh, N. S., \& Reddy, S. K. (2014). Ratings lead you to the product, reviews help you clinch it? the mediating role of online review sentiments on product sales. Decision Support Systems, 57(1), 42-53. doi:10.1016/j.dss.2013.07.009

Ismail, E. A. M. (2019). Modelling the relationship between hotel perceived value, customer satisfaction, and customer loyalty. Journal of Retailing and Consumer Services, 50, 322-332. doi:10.1016/j.jretconser.2018.07.007

Jiang, H., Kwong, C. K., \& Yung, K. L. (2017). Predicting future importance of product features based on online customer reviews. Journal of Mechanical Design, 139(11), 111413.1-111413.10. 10.1115/1.4037348

Jointwisdom. (2020). White Paper on Hotel Accommodation in 2019. Retrieved from https://www.jointwisdom. $\mathrm{cn} / \mathrm{report}-\mathrm{list} / 175 . \mathrm{html}$

Kandampully, J. A., \& Suhartanto, D. (2000). Customer loyalty in the hotel industry: The role of customer satisfaction and image. International Journal of Contemporary Hospitality Management, 12(6), 3-25. doi:10.1108/09596110010342559

Kang, Y., \& Zhou, L. (2017). Rube: Rule-based methods for extracting product features from online consumer reviews. Information \& Management, 54(2), 166-176. doi:10.1016/j.im.2016.05.007

Kano, N., Seraku, N., Takahashi, F., \& Tsuji, S. (1984). Attractive quality and must-be quality. Journal of the Japanese Society for Quality Control, 4, 39-48.

Khotimah, D. A., \& Sarno, R. (2019). Sentiment Analysis of Hotel Aspect Using Probabilistic Latent Semantic Analysis, Word Embedding and LSTM. International Journal of Intelligent Engineering and Systems, 12(4), 275-290. doi:10.22266/ijies2019.0831.26

Kim, S. B., \& Kim, D. Y. (2017). Antecedents of Corporate Reputation in the Hotel Industry: The Moderating Role of Transparency. Sustainability, 9(6), 1-15. doi:10.3390/su9060951

Kim, S. H., Cha, J., Singh, A. J., \& Knutson, B. (2013). A longitudinal investigation to test the validity of the American customer satisfaction model in the US hotel industry. International Journal of Hospitality Management, 35, 193-202. doi:10.1016/j.jhm.2013.05.004

Kristensen, K., Martensen, A., \& Gronholdt, L. (1999). Customer satisfaction measurement at Post Danmark. Total Quality Management, 11(7), 1007-1015. doi:10.1080/09544120050135533

Li, H., Ye, Q., \& Law, R. (2013). Determinants of customer satisfaction in the hotel industry: An application of online review analysis. Asia Pacific Journal of Tourism Research, 18(7), 784-802. doi:10.1080/10941665. 2012.708351

Li, J., Liu, M., Li, X., Liu, X., \& Liu, J. (2018). Developing embedded taxonomy and mining patients' interests from web-based physician reviews: Mixed-methods approach. Journal of Medical Internet Research, 20(8), 28. doi:10.2196/jmir.8868 PMID:30115610

Liu, B. (2010). Sentiment analysis and subjectivity. In Handbook of Natural Language Processing (2 $2^{\text {nd }}$ ed.). CRC Press. 
Liu, Q., \& Li, S. J. (2002). Word Similarity Computing based on HowNet. Computational Linguistics and Chinese Language Processing, 17(2), 59-76.

Lucini, F. R., Tonetto, L. M., Fogliatto, F. S., \& Anzanello, M. J. (2020). Text mining approach to explore dimensions of airline customer satisfaction using online customer reviews. Journal of Air Transport Management, 83, 101760. Advance online publication. doi:10.1016/j.jairtraman.2019.101760

Luo, J., Huang, S. S., \& Wang, R. (2020). A fine-grained sentiment analysis of online guest reviews of economy hotels in china. Journal of Hospitality Marketing \& Management, 30(1), 71-95. doi:10.1080/19368623.2020 .1772163

Martilla, J. A., \& James, J. C. (1977). Importance-Performance Analysis. Journal of Marketing, 41(1), 77-79. doi:10.1177/002224297704100112

Mikolov, T., Chen, K., Corrado, G., \& Dean, G. (2013). Efficient Estimation of Word Representations in Vector Space. Computer Science, 1-12.

Nunkoo, R., Teeroovengadum, V., Ringle, C. M., \& Sunnassee, V. (2020). Service quality and customer satisfaction: The moderating effects of hotel star rating. International Journal of Hospitality Management, 91, 102414. Advance online publication. doi:10.1016/j.ijhm.2019.102414

Oliver, R. L. (1980). A Cognitive Model of the Antecedents and Consequences of Satisfaction Decisions. JMR, Journal of Marketing Research, 17(4), 460-469. doi:10.1177/002224378001700405

Pacheco, L. (2017). Customer satisfaction in portuguese hotels: Evidence for different regions and hotel segments. Tourism Analysis, 22(3), 337-347. doi:10.3727/108354217X14955605216087

Pang, B., \& Lee, L. L. (2008). Opinion Mining and Sentiment Analysis. Foundations \& Trends in Information Retrieval, 2(1-2), 1-135. doi:10.1561/1500000011

Parasuraman, A., Zeithaml, V. A., \& Berry, L. L. (1985). A conceptual model of service quality and its implications for future research. Journal of Marketing, 49(4), 41-50. doi:10.1177/002224298504900403

Parasuraman, A., Zeithaml, V. A., \& Berry, L. L. (1988). SERVQUAL: A Multiple-Item Scale for Measuring Consumer Perceptions of Service Quality. Journal of Retailing, 64(1), 12-40.

Pekar, V., \& Ou, S. (2008). Discovery of subjective evaluations of product features in hotel reviews. Journal of Vacation Marketing, 14(2), 145-155. doi:10.1177/1356766707087522

Pizam, A., \& Ellis, H. (1999). Customer satisfaction and its measurement in hospitality enterprises. International Journal of Contemporary Hospitality Management, 11(7), 326-339. doi:10.1108/09596119910293231

Pizam, A., Shapoval, V., \& Ellis, T. (2016). Customer satisfaction and its measurement in hospitality enterprises: A revisit and update. International Journal of Contemporary Hospitality Management, 28(1), 2-35. doi:10.1108/ IJCHM-04-2015-0167

Priyantina, R. A., \& Sarno, R. (2019). Sentiment Analysis of Hotel Reviews Using Latent Dirichlet Allocation, Semantic Similarity and LSTM. International. Journal of Intelligent Engineering and Systems, 12(4), 142-155. doi:10.22266/ijies2019.0831.14

Qi, J., Zhang, Z., Jeon, S., \& Zhou, Y. (2016). Mining customer requirements from online reviews: A product improvement perspective. Social Science Electronic Publishing, 53(8), 951-963. doi:10.1016/j.im.2016.06.002

Rahimi, R., \& Kozak, M. (2017). Impact of customer relationship management on customer satisfaction: The case of a budget hotel chain. Journal of Travel \& Tourism Marketing, 34(1), 40-51. doi:10.1080/10548408.2 015.1130108

Rossomme, J. (2003). Customer satisfaction measurement in a busines-to-business context: A conceptual framework. Journal of Business and Industrial Marketing, 18(2), 179-195. doi:10.1108/08858620310463097

Shafiq, A., Mostafiz, M. I., \& Taniguchi, M. (2019). Using SERVQUAL to determine Generation Y's satisfaction towards hoteling industry in Malaysia. Journal of Tourism Futures, 5(1), 62-74. doi:10.1108/JTF-01-2018-0004 
Sun, Q., Niu, J., Yao, Z., \& Yan, H. (2019). Exploring eWOM in online customer reviews: Sentiment analysis at a fine-grained level. Engineering Applications of Artificial Intelligence, 81(5), 68-78. doi:10.1016/j. engappai.2019.02.004

Tao, W., Zhang, Q., Zhang, M., \& Li, Y. (2019). Mining Pain Points from Hotel Online Comments based on Sentiment Analysis. In 2019 IEEE 8th Joint International Information Technology and Artificial Intelligence Conference (ITAIC). IEEE.

Tsai, Y. T., Gotcher, D., Kim, S. H., Pan, R. B., \& Wu, T. H. (2020). Exploring service quality combining kano model and importance-performance analysis customer satisfaction of luxury housing service management. International Journal of Services Economics and Management, 11(1), 71-95. doi:10.1504/IJSEM.2020.10028626

Wei, X., Luo, X., Li, Q., Zhang, J., \& Xu, Z. (2015). Online Comment-Based Hotel Quality Automatic Assessment Using Improved Fuzzy Comprehensive Evaluation and Fuzzy Cognitive Map. IEEE Transactions on Fuzzy Systems, 23(1), 72-84. doi:10.1109/TFUZZ.2015.2390226

Wen, B., Dai, W. H., \& Zhao, J. Z. (2012). Sentence Sentimental Classification Based on Semantic Comprehension. In 2012 Fifth International Symposium on Computational Intelligence and Design. IEEE. doi:10.1109/ISCID.2012.275

Xu, X., \& Li, Y. (2016). The antecedents of customer satisfaction and dissatisfaction toward various types of hotels: A text mining approach. International Journal of Hospitality Management, 55, 57-69. doi:10.1016/j. ijhm.2016.03.003

Yaleimeng. (2019).Final_word_Similarity. Retrieved from https://github.com/yaleimeng/Final_word_Similarity

Yan, X. H., Guo, J. F., Lan, Y. Y., \& Chen, X. Q. (2013). A biterm topic model for short texts. In Proceedings of the 22nd International Conference on World Wide Web (WWW'13). Association for Computing Machiner. doi: $10.1145 / 2488388.2488514$

Yao, C. L. (2012). Application of Gray Relational Analysis Method in Comprehensive Evaluation on the Customer Satisfaction of Automobile 4S Enterprises. Physics Procedia, 33, 1184-1189. doi:10.1016/j.phpro.2012.05.194

Yu, L. C., Wang, J., Lai, K. R., \& Zhang, X. (2017). Refining word embeddings using intensity scores for sentiment analysis. IEEE/ACM Transactions on Audio, Speech, and Language Processing, 26(3), 671-681. doi:10.1109/TASLP.2017.2788182

Zhang, C. X., Zhao, M., Cai, M. Y., \& Xiao, Q. R. (2020). Multi-stage multi-attribute decision making method based on online reviews for hotel selection considering the aspirations with different development speeds. Computers \& Industrial Engineering, 143(5), 106421.1-106421.18. 10.1016/j.cie.2020.106421

Zhang, D., Xu, H., Su, Z., \& Xu, Y. (2015). Chinese comments sentiment classification based on word2vec and SVM ${ }^{\text {perf }}$. Expert Systems with Applications, 42(4), 1857-1863. doi:10.1016/j.eswa.2014.09.011

Zhang, X. J., \& Li, H. M. (2009). Budget hotel customer satisfaction analysis based on SERVQUAL model. Strategic Management Engineering: Enterprise. Environment and Crisis, 1, 64-68.

Gang Zhou is a doctoral student in the department of marketing at Chongqing University, as well as an associate professor in the department of hospitality management at Chongqing Normal University. His research areas focus on tourist behavior, service marketing, natural language processing, hotel management and long stay tourism.

Chenglin Liao $(P h D)$ is a professor as well as a doctoral supervisor in the department of marketing at Chongqing University. His main research interests include corporate management, marketing management, and e-commerce. 